\title{
The role of the liver in the control of food intake
}

\section{By J. M. Forbes, Department of Animal Physiology and Nutrition, University of Leeds LS2 $9 \mathfrak{F T}$}

The liver is at the crossroads of metabolism, being in the unique position of receiving almost all of the absorbed nutrients some of which it takes up to replenish its glycogen stores. It is therefore ideally suited to be an important monitor of nutrient flow into the animal and evidence has been accumulating during the last decade that food intake in a variety of species responds to the energy status of the liver, which is relayed to the brain by hepatic branches of the vagus nerve.

\section{Effects of manipulation of liver metabolism on food intake}

For many years the sole champion of the importance of the liver in the control of food intake was Russek (see Russek, I963). He and his colleagues used a variety of procedures to alter the glucose concentration of hepatocytes, including comparisons of the effects of portal and jugular infusions of glucose (Russek, I 970) and intraperitoneal injection of substances known to affect liver glucose concentration (Russek \& Stevenson, 1972). They showed an inverse relationship between the concentration of glucose and food intake. Their contention, that this was a causal relationship, mediated by the vagus nerve, was supported by the demonstration that afferent activity in the hepatic branch of the vagus of isolated guinea-pig liver was inversely correlated with the glucose concentration of the perfusate (Niijima, I969). It seems unlikely that the liver could monitor the concentration of glucose passing through it in the blood, but a plausible hypothesis of how the liver might respond to its own rate of uptake or release of nutrients has been proposed by Russek (1976). He suggested that a change in hepatocyte membrane potential, proportional to the flow of metabolites into or out of the cell, could be relayed via the hepatic branches of the vagus nerve.

Blockage of glucose uptake by the liver, by means of 2-deoxy-glucose (2DG) infusion into the hepatic portal vein, caused increased feeding in rabbits (Novin et al. 1973), while similar infusions into the jugular vein were much less effective; vagotomy reduced the effectiveness of portal vein $2 \mathrm{DG}$ to the level of jugular infusion. In rabbits with free access to food, glucose infused into the portal vein did not have the expected effect of depressing feeding (Novin et al. 1974), but did reduce food intake in animals which had been deprived of food for $22 \mathrm{~h}$ before the test; the explanation might be that the liver is always replete in rabbits fed ad lib. so that glucose is not taken up by this organ and that satiety is not induced by portal glucose infusion unless liver glycogen has been significantly reduced by an enforced fast. In contrast to these observations, Strubbe \& Steffens ( 1977) found 
that there was gross elevation of glucose concentrations in portal veins after infusion in rats starved for $22 \mathrm{~h}$ and that there was no effect on food intake.

In ruminants there is relatively little absorption of glucose from the digestive tract and propionate is the major precursor of glucose, much of the propionate flowing in the portal vein being taken up by the liver for glycogenesis. It was, therefore, particularly interesting to find that, of the three major volatile fatty acids produced in the rumen, propionate was the most effective in depressing voluntary intake when infused into the portal vein of sheep (Anil \& Forbes, 1980) or ruminal vein of goats (Baile, I971). Furthermore, portal infusion of sodium propionate, at somewhat supraphysiological rates, had a much greater hypophagic effect than infusion into the jugular vein. Furthermore, selective section of the vagal branches very close to the liver blocked the effect of portal infusion of propionate (Anil \& Forbes, 1980 ). It appears, therefore, that the ruminant liver monitors its uptake of propionate in a manner analagous to glucose in simple-stomached animals. It must be mentioned at this point that de Jong ( $198 \mathrm{I}$ ), after very careful experimental work, has failed to demonstrate a specific, physiological effect of portal propionate infusion on the voluntary intake of goats.

The chicken has recently been the subject of studies of glucose infusions into the hepatic portal vein (Shurlock \& Forbes, I98I) in which it was shown that the infusion of $84 \mathrm{mg}$ glucose/min for $3 \mathrm{~h}$ depressed intake to a much greater extent than did similar infusion into the jugular vein. The hepatic effect was dose-dependent, with maximal depression of intake during infusions in the range of I I to $22 \mathrm{mg} / \mathrm{min}$, i.e. physiological rates. In contrast to the observations of Novin et al. (1974) with rabbits, fasting the birds was not a necessary prerequisite for this response. Perhaps the fed bird is similar to the fasted rabbit in that liver stores of glycogen may be low in both cases.

In a similar experiment with young pigs, using $500 \mathrm{ml}$ glucose solution ( $15^{\circ} \mathrm{g} / \mathrm{l}$ ) infused over to min into jugular or portal vein, there was no effect on feeding (Stephens \& Baldwin, 1974). Infusion of glucose solution (400 g/l) at $5 \mathrm{ml} / \mathrm{kg}$ body-weight over $10 \mathrm{~min}$ into the duodenum of pigs severely depressed intake, but similar infusions into portal or jugular veins had no effect (Houpt $e t$ al. 1979). The liver may, therefore, be less important in the regulation of feeding in the pig than it appears to be in some other species, although it must be noted that both of these experiments with pigs used high concentrations of glucose infused over short periods into previously fasted animals.

\section{Role of the liver in the integrated control of food intake}

So far we have considered only those feed-back signals which appear to result from glucose uptake or release by the liver. There are several other stimuli which have been shown to depress feeding and to be likely satiety signals: for example, increased duodenal glucose concentration or distension of several parts of the digestive tract. In the ruminant no single stimulus has been shown to be able to account for satiety; propionate has to be infused into the portal vein at approximately twice the maximal postprandial rate of absorption in order to 
suppress feeding completely and distension of the rumen with a balloon does not depress roughage intake in proportion to the estimated reduction in rumen capacity. During the course of a spontaneous meal there are, of course, small increases in all of the chemical and mechanical stimuli which have been shown to inhibit feeding and we have suggested that the sum total of these small changes might be sufficient to explain satiety (Forbes, r 980 ). As a first step towards testing this hypothesis we have examined the effects of the following on the food intake of sheep: (a) infusing propionate intra-portally and (b) inflating a balloon in the rumen, either separately or together (Adams \& Forbes, 1981). When these stimuli were applied for $3 \mathrm{~h}$ at physiological levels $(0.6 \mathrm{mmol}$ propionate $/ \mathrm{min}$, I 1 balloon) their effects on concurrent food intake were additive. Similarly, the effects of propionate into the portal vein $(0.6 \mathrm{mmol} / \mathrm{min})$ and acetate into the rumen ( $2 \mathrm{mmol} / \mathrm{min}$ ) were also additive. A parallel experiment with chickens also showed additivity between the intake-depressing effects of a glucose load injected into the crop of chickens ( 3.6 or $10.8 \mathrm{~g}$ ) and $3 \mathrm{~h}$ infusions of glucose into the portal vein $(5.3$ or $84 \mathrm{mg} / \mathrm{min}$ ) (Shurlock \& Forbes, I98I). So far the evidence supports a multifactorial control of food intake, with the liver playing an important, but not overriding, part.

The fact that transplantation of the liver, which ensures its complete denervation, does not result in grossly abnormal food intake (see Stephens \& Baldwin, I 974) emphasises that other mechanisms are capable of controlling food intake. A detailed study of feeding behaviour in liver-denervated sheep showed that although daily intake was not affected, meals were larger and less frequent (Anil \& Forbes, 1980). Vagotomized rabbits also took larger meals than sham-operated controls, although their daily intake was reduced (Rezek et al. I975).

In a review as short as this it is impossible to do justice to a topic of this nature. We are fortunate, therefore, to have the excellent and comprehensive review on the integration of the peripheral and central control of intake by Novin \& Van der Weele (1977), to which all interested readers are directed.

\section{REFERENCES}

Adams, G. B. \& Forbes, J. M. (I98I). Proc. Nutr. Soc. 40, 44A.

Anil, M. H. \& Forbes, J. M. (1980). F. Physiol., Lond. 298, 407.

Baile, C. A. (1971). Physiol. Behav. 7,819.

de Jong, A. (I 981 ). PhD thesis, University of Groningen, Netherlands.

Forbes, I. M. (1980). Ann. Zootech. 29, I8g.

Houpt, K. A., Houpt, T. R. \& Pond, W. G. (1979). Yale F. biol. Med. 52, 307.

Niijima, A. (1969). Ann. N.Y. Acad. Sci. 157,69o.

Novin, D., Sanderson, J. D. \& Van der Weele, D. A. (1974). Physiol. Behav. 13, 3.

Novin, D. \& Van der Weele, D. A. (1977). In Progress in Psychobiology and Physiological Psychology, Vol. 7 [J. M. Sprague and A. N. Epstein, editors]. New York: Academic Press.

Novin, D., Van der Weele, D. A. \& Rezek, M. (1973). Science, N.Y. I81, $85^{8}$.

Rezek, M., Schneider, K. \& Novin, D. (1975). Physiol. Behav. 15, 5 17.

Russek, M. (1963). Nature, Lond. 200, i 76.

Russek, M. (1970). Physiol. Behav. 5, 1207 .

Russek, M. (1976). In Hunger: Basic Mechanisms and Clinical Implications [D. Novin, W. Wyrwicka and G. Bray, editors]. New York: Raven Press. 
Russek, M. \& Stevenson, J. A. F. (1972). Physiol. Behav. 8, 245.

Shurlock, T. G. H. \& Forbes, J. M. (1981). Br. Poult. Sci. 22, 333.

Stephens, D. B. \& Baldwin, B. A. (1974). Physiol. Behav. 12, 923.

Strubbe, J. H. \& Steffens, A. B. (1977). Physiol. Behav. 19, 303. 